\title{
Bacterial Foraging Algorithm Based Parameter Estimation of Three Winding Transformer
}

\author{
Srikrishna Subramanian, Seeni Padma \\ Department of Electrical Engineering, FEAT, Annamalai University, \\ Annamalainagar, India \\ E-mail:profdrmani@gmail.com,padma_pnr@yahoo.co.in \\ Received February 7, 2011; revised March 23, 2011; accepted April 2, 2011
}

\begin{abstract}
Transformers are one of the main components of any power system. An accurate estimation of system behaviour, including load flow studies, protection, and safe control of the system calls for an accurate equivalent circuit parameters of all system components such as generators, transformers, etc. This paper presents a methodology to estimate the equivalent circuit parameters of the Three Winding Transformer (TWT) using Bacterial Foraging Algorithm (BFA). The estimation procedure is based on load test data at one particular operating point namely supply voltage, load currents, input power. The performance characteristics, such as efficiency and voltage regulation are considered along with the name plate data in order to minimize the error between the estimated and measured data. The estimation procedure is demonstrated with a sample three winding transformer and the results are compared against the directly measured performance of TWT and genetic algorithm optimization results. The simulation results show the ability of the proposed technique to capture the true values of the machine parameters and the superiority of the results obtained using the bacterial foraging algorithm.
\end{abstract}

Keywords: Parameter Estimation, Three Winding Transformer, Bacterial Foraging Algorithm

\section{Introduction}

Three winding transformers (TWT) are widely used in power system and power electronic applications. Determination of its equivalent circuit parameters is useful in performance computations, power system load flow studies etc. Measurement or computation of equivalent circuit parameters of TWT is difficult and unreliable due to the complexity of the geometry of the windings. Various methodologies were applied for parameter estimation of transformer equivalent circuit. The equivalent circuit parameters of three winding transformer are determined based on Genetic Algorithm (GA) [1] has been discussed. The ferroresonance of the transformer has been predicted or confirmed and its severity can be evaluated by using transformer equivalent circuit models [2]. A topology-based and duality derived three-phase three winding core type transformer model has been developed and it treats the leakage inductances and the coupling effects of the core in a straightforward and integrated way [3]. The method based on Genetic Algorithm (GA) has been developed for the identification of synchronous machine parameters from short circuit tests [4]. GA has also been applied to determine the electric parameters of an induction machine using Park model [5]. The Park model electric parameters of an induction machine [6] are used in control techniques for variable speed drives, have been estimated by GA.

The average winding temperature rise under its field operation conditions and rise in winding temperature has been determined from the estimated values of winding resistance [7]. The parameters of a saturation model of transformer are also estimated by using the data from transformer inrush tests and steady state operation [8]. An alternative approach to conventional open and shortcircuit test for determining the parameters of $\mathrm{N}$-windings transformer operating at power frequency on an on-line mode. The method is based on linear Least Error Square (LES) algorithm and uses the digitized samples of the input current and voltage as well as the output current and voltage of the transformer windings [9]. The GA based method has also been suggested to identify the parameters of an induction motor [10].

The conventional model for multiwinding transform- 
ers is difficult to relate to its physical construction, and the measurement of the model parameters is also difficult and unreliable, [11] hence a physically based electrical model of a high voltage multiwinding transformers has been developed. In this model, each component corresponds to a physical quantity of the transformer and the leakage inductance for nonuniformly spaced windings, which store significant energy in the flux in the radial field, has also been easily calculated.

Differential evolution algorithm [12] has been applied for parameter identification of an induction motor. Parameter identification of an induction machine using GA [13] has been discussed for variable speed applications. The general mathematical model of the motor based upon Kron's voltage equations has been considered to estimate the parameters and the start-up performance of the motor has been used as the measurement for identification process. A multi-stage transformer model [14] for high frequency transient operation is established, and the equivalent circuit parameters are estimated by using their mathematical formulation. The modified version of GA namely, enhanced GA [15] which operates on real-valued parameter sets and provides an improvement in the solution quality, has been applied to determine the equivalent circuit parameters of induction motors.

Sensitivity of estimated parameters in transformer thermal modeling has been discussed [16]. Least Squares Method [17] has been applied to estimate the transformer equivalent circuit parameters, also determined the optimal approximation polynomial functions for each parameter. Artificial Neural Networks (ANN) based method has been suggested for estimation of electrical losses in the three-phase distribution transformer [18]. Electronic transformer model has been developed and also estimate the equivalent circuit parameters are presented in [19]. Recursive least squares routine [20] has been applied to estimate the on line dynamic parameters for transformer.

The modern heuristic search technique, called Bacterial Foraging Algorithm (BFA) has been developed based on modelling of bacteria $E$. coli behavior present in human intestine and it has been proven that is efficient [21-26] for various engineering optimization problems. In this article, BFA has been applied to estimate the equivalent circuit parameters of three phase transformer. The effectiveness of the proposed BFA approach has been tested with the suitable transformer.

\section{Problem Description and Formulation}

The parameter estimation is one of the important problems to solve in the system studies. The conventional method of parameter determination using short-circuit test data provides an approximate equivalent circuit.
Equivalent circuit model of a TWT is shown in Figure 1.

This method requires a minimum of two tests namely short circuit test and direct current resistance test are conducted at supply conditions different from normal operation. In addition to that empiricism exists in the allocation of leakage reactance between primary, secondary and tertiary windings. The performance evaluation of transformer using the equivalent circuit parameters is inaccurate because the change in the winding resistance due to temperature rise which is caused by loading effect is ignored in the conventional method. Apart from that the stray-load loss component is not accounted. For the above reason, the exact equivalent circuit model of transformer has been formulated by including the load impedance as shown in Figure 2.

The following equations are used to estimate the equivalent circuit parameter. Let the impedance of the primary secondary, tertiary windings referred to primary side are

$$
\begin{gathered}
z_{1}=\sqrt{r_{1}^{2}+x_{1}^{2}} \\
z_{2}^{\prime}=\sqrt{\left(r_{2}^{\prime}+r_{l 2}^{\prime}\right)^{2}+\left(x_{2}^{\prime}\right)^{2}} \\
z_{3}^{\prime}=\sqrt{\left(r_{3}^{\prime}+r_{l 3}^{\prime}\right)^{2}+\left(x_{3}^{\prime}\right)^{2}}
\end{gathered}
$$

Then the admittance of the magnetizing winding is

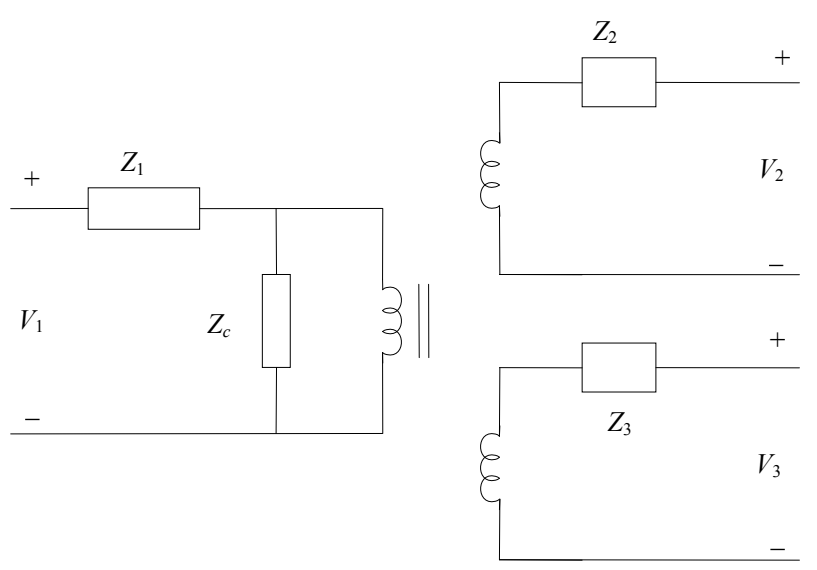

Figure 1. Equivalent circuit model of TWT.

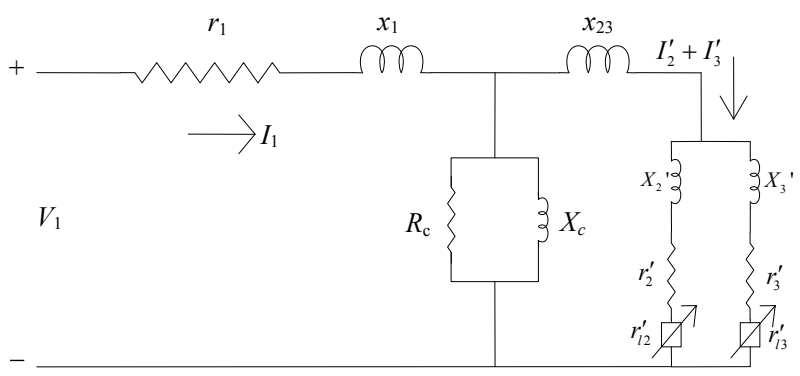

Figure 2. Exact equivalent circuit model of a TWT. 


$$
\begin{gathered}
Y_{c}=\frac{1}{R_{c}}-\frac{1}{X_{c}} \\
Z_{c}=\frac{1}{Y_{c}}
\end{gathered}
$$

The equivalent impedance of secondary and tertiary winding referred to primary side is

$$
Z_{23}^{\prime}=Z_{23}^{\prime}+\frac{Z_{2}^{\prime} Z_{3}^{\prime}}{Z_{2}^{\prime} Z_{3}^{\prime}}
$$

The estimated value of the equivalent impedance as referred to primary side is

$$
Z_{\text {lest }}=Z_{1}+\frac{Z_{23}^{\prime} Z_{c}}{Z_{23}^{\prime}+Z_{c}^{\prime}}
$$

The estimated value of primary voltage be

$$
V_{\text {lest }}=Z_{\text {lest }} I_{1}
$$

And the estimated value of input power be

$$
P_{\text {lest }}=P_{\text {core }}+P_{1 c u}+P_{2 c u}+P_{3 c u}+P_{2}+P_{3}
$$

The objective of the parameter problem is to find a set of equivalent circuit parameters that minimizes the error. The equivalent circuit parameters are to be estimated by minimizing the following objective function,

$$
f(X)=f_{1}^{2}+f_{2}^{2}
$$

where

$$
\begin{gathered}
X=r_{1}, x_{1}, x_{23}^{\prime}, r_{2}^{\prime}, x_{2}^{\prime}, r_{3}^{\prime}, x_{3}^{\prime}, R_{c}, X_{c} \\
f_{1}=\frac{V_{1 m e s}-V_{1 e s t}}{V_{1 m e s}} * 100 \\
f_{2}=\frac{P_{1 \text { mes }}-P_{1 e s t}}{P_{1 \text { mes }}} * 100
\end{gathered}
$$

\section{Bacterial Foraging Optimization}

The selection behaviour of bacteria tends to eliminate poor foraging strategies and improve successful foraging strategies. After many generations a foraging animal takes actions to maximize the energy obtained per unit time spent foraging. This activity of foraging led the researchers to use it as optimization process. The E coli bacterium has a control system that enables it to search for food and try to avoid noxious substances. The bacteria distributed motion can model as the following four stages:

\subsection{Swarming and Tumbling via Flagella $\left(N_{s}\right)$}

The flagellum is a left-handed helix configured so that as the base of the flagellum (i.e. where it is connected to the cell) rotate counter clockwise, from the free end of the flagellum looking towards the cell, it produces a force against the bacterium pushing the cell. This mode of motion is called swimming. A bacterium swims either for maximum number of steps Ns or less depending on the nutrition concentration and environment condition. During clockwise rotation each flagellum pulls on the cell shown in Figure 3. So that the net effect is that each flagellum operates relatively independently of the others and so the bacterium "tumbles".

\subsection{Chemotaxis $\left(N_{c}\right)$}

A chemotaxis step is a set of consequence swim steps following by a tumble. A maximum of swim steps with a chemotactic step is predefined by Ns. The actual number of swim steps is determined by the environment. If the environment shows good nutrients concentration in the direction of the swim, the bacteria swim more steps. When the swim steps is stopped a tumble action takes place.

\subsection{Reproduction $\left(N_{r e}\right)$}

After $N_{c}$ chemotactic steps, a reproduction step is taken. Let Nre be the number of reproduction steps to be taken. It is assumed that half of the population members have sufficient nutrients so that they will reproduce with no mutations. For reproduction, the population is sorted in order of ascending accumulated cost accumulated cost represents that it did not get as many nutrients during its lifetime of foraging and hence, is not as "healthy" and

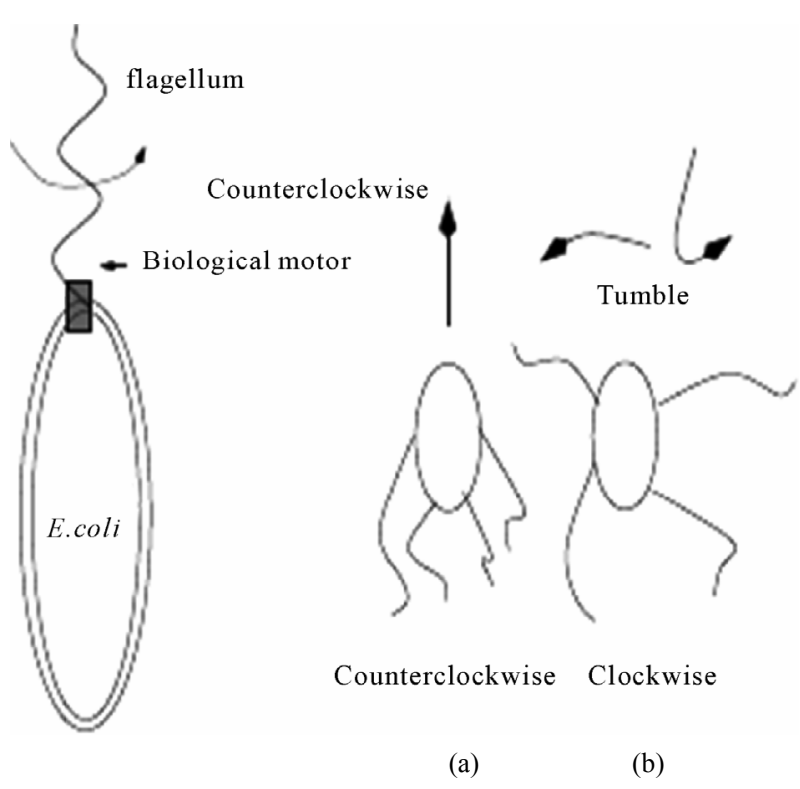

Figure 3. Swarming and tumbling behaviour. 
thus unlikely to reproduce).Least healthy group of bacteria dies out and the other healthiest splits into two.

\subsection{Elimination and Dispersal $\left(N_{e d}\right)$}

Elimination event may occur for example when local significant increases in heat kill a population of bacteria that are currently in a region with a high concentration of nutrients. A sudden flow of water can dispose bacteria from one place to another. The effect of elimination and dispersal event is possibly destroying chemotactic progress, but they also have the effect of assisting in Chemotaxis, since dispersal may place bacteria near good food sources. The flowchart for BFA is depicted in Figure 4.

\section{BF Algorithm to Estimation of Transformer Equivalent Parameter}

The proposed method is employed to search the optimal equivalent circuit parameters for the three winding transformer. Each bacterium contains nine members: $r_{1}$, $x_{1}, x_{23}^{\prime}, r_{2}^{\prime}, x_{2}^{\prime}, r_{3}^{\prime}, x_{3}^{\prime}, R_{c}$ and $X_{c}$. If there is s number of bacteria in a population, then the dimension of population is $s \times 9$. The process of estimate the equivalent circuit parameters of the transformer can be explained as follows: First input the bacterial foraging parameters and conventional measured data, and also specify lower and upper limits of the equivalent circuit parameters. Generate the positions of the equivalent circuit parameter randomly and evaluate the objective value of each bacterium. After evaluating the objective function, modify the position of the equivalent circuit parameters for all the bacteria using the tumbling/ swimming process and perform reproduction and elimination operation. The output of equivalent circuit parameters are obtained when the maximum steps is reached. Finally, compute the operating performances of the transformer such as efficiency and regulation. In proposed method, the process of "chemotaxis" enables bacteria to obtain a satisfactory ability of local search. It is worth notice that the individuals in bacterial foraging algorithm could converge rapidly without information sharing between each other, which is different from other methods.

The algorithm for proposed method as follows

Step 1: Initialize parameters $P, s, N_{r e}, N_{e d}, P_{e d}, C(i)$ $(i=1,2, \cdots, s)$, and $X_{i}$. Also initialize all the counter values to zero.

Step 2: Elimination-dispersal loop: $l=l+1$

Step 3: Reproduction loop: $k=k+1$

Step 4: Chemotaxis loop: $j=j+1$

1) For $i=1,2, \cdots, s$, calculate cost function value and efficiency- for each bacterium $i$ as follows.
- $\quad N_{i s}$ signal samples are passed through the model.

- The output is then compared with the corresponding desired signal to calculate the error.

- The same of the squared error averaged over $N_{i s}$ is finally stored in $J(i, j, k, l)$. The cost function is calculated for number of input samples.

- End of for loop.

2) For $i=1,2, \cdots, s$, take the tumbling/swimming decision

Tumble: Generate a random vector $\Delta(i)$ with each element $\Delta_{m}(i) m=1,2, \cdots, p$, a random number.

Move: Let

$$
\theta^{i}(j+l, k, l)=\theta^{i}(j, k, l)+C(i) \frac{\Delta(i)}{\sqrt{\Delta^{T}(i) \Delta(i)}}
$$

Fixed step size in the direction of tumble for bacterium $i$ is considered.

Compute $J(i, j+1, k, l)$ and then

Let

$$
\begin{aligned}
J_{S w}(i, j+1, k, l)= & J(i, j+1, k, l) \\
& +J_{c c}\left(\theta^{i}(j+1, k, l), P(j+1, k, l)\right)
\end{aligned}
$$

Swim:

a) Let $m=0$; (counter for swim length)

b) While $m<N_{s}$ (have not climbed down too long)

- Let $m=m+1$

- If $J_{S w}(i, j+1, k, l)<J_{\text {last }}$ (if doing better), let $J_{\text {last }}=$ $J_{S w}(i, j+1, k, l)$ and Let

$$
\theta^{i}(j+l, k, l)=\theta^{i}(j, k, l)+C(i) \frac{\Delta(i)}{\sqrt{\Delta^{T}(i) \Delta(i)}}
$$

And use this $\theta^{i}(j+1, k, l)$ to compute the new $J(i, j+$ $1, k, l)$

- Else, let $m=N_{s}$. This is the end of the while statement.

3) Go to next bacterium $(i+1)$ if $i \neq \mathrm{s}$ (i.e. go to b) to process the next bacterium.

Step 5: If $j<N_{c}$, go to step 4. In this case, continue Chemotaxis since the life of the bacteria is not over.

Step 6: Reproduction:

1) For the given $k$ and $l$, and for each $i=1,2, \cdots, s$,

Let $J_{\text {health }}^{i}=\min J_{S w}(i, j, k, l)$ be the health of the bacterium $i$ (a measure of how many nutrients it got over its life time and how successful it was at avoiding noxious substance). Sort bacteria in order of ascending cost $J_{\text {health }}$ (higher cost means lower health).

2) The $S_{r}=s / 2$ bacteria with highest $J_{\text {health }}$ values die and other $S_{r}$ bacteria with the best value split (and the copies that are made are placed at the same location as their parent)

Step 7: If $k<N_{\text {re }}$ go to 3. In this case, the number of specified reproduction steps has not been reached, so the 
next generation of the chemotactic loop is started.

Step 8: Elimination-dispersal: For $i=1,2, \cdots, s$, with probability $P_{e d}$, eliminates and disperses each bacterium (this keeps the number of bacteria in the population constant). To do this, if a bacterium is eliminated, simply disperse another one to a random location on the optimization domain. If $l<N_{e d}$, then go to step 2; otherwise, print the results and stop.

\section{Results and Discussions}

To validate the feasibility, the proposed method have been employed for parameter estimation of single phase, $5 \mathrm{KVA}, 220 \mathrm{~V}, 50 \mathrm{~Hz}$, three winding transformer. Load test data and computed performance characterises of TWT half to full load condition are presented in Table $\mathbf{1 .}$

The equivalent circuit parameters are also determined by performing the suitable tests and the predetermined efficiency and voltage regulation are compared with the load test values which are presented in Table 2. Comparsion of these two performances shows that there is a deviation in the values of efficiency and regulation. By estimating the accurate value of equivalent circuit parameters, the deviation can be minimized. Hence the problem has been formulated as an error minimization problem and the modern heuristic search technique, BFA has been applied to obtain the optimal value of equivalent circuit parameters.

The parameters of the BFA used for the simulation studies are summarized in Table 3 . The best results are obtained from 20 trail runs and are reported in Table 4. For the sake of comparison, rated load condition is considered and the efficiency and voltage regulation at rated load are predetermined by using the estimated equivalent circuit parameters. The simulation results obtained by the proposed method are compared with actual load test measurements and Genetic Algorithm (GA) based results, the comparison is given in Table 4. From the comparison, it is revealed that an improvement in the predetermined efficiency and voltage regulation. The simulation has been performed to various load conditions. For each load conditions, the efficiency and voltage regulation are computed. Comparative studies with actual load test measurement, GA and BFA are presented in Table 5.

In addition, the percentage of error over the load test measurement is computed and is also presented in Table 5. The comparison clearly shows the reduction in error between the actual and estimated data. BFA based estimation of equivalent circuit parameters values are close to directly measured values. This facts lead to a conclusion that the proposed methodology provide to global optimum solutions. Figures $\mathbf{5}$ and $\mathbf{6}$ shows the performance curve of efficiency and regulation obtained from

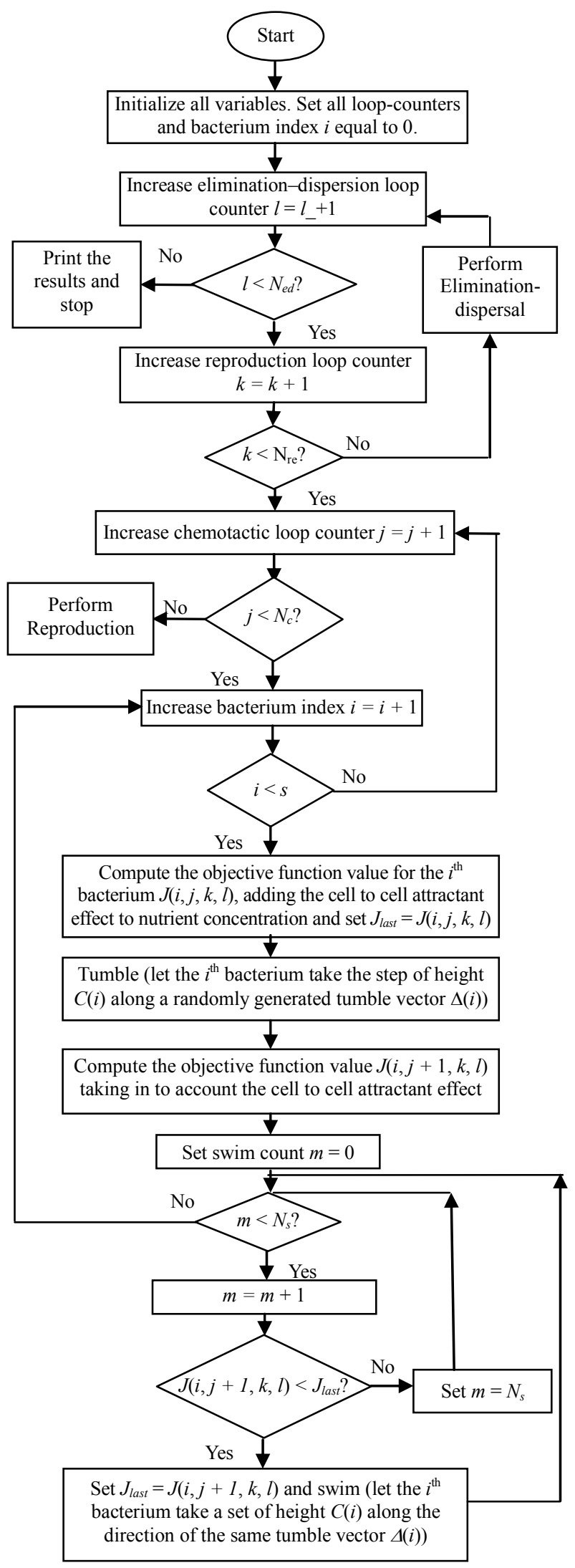

Figure 4. Flow chart for bacterial foraging algorithm. 
Table 1. Load test data of a single phase TWT at $220 \mathrm{~V}, 50 \mathrm{~Hz}$ supply.

\begin{tabular}{ccccccccccc}
\hline Load (\%) & $I_{1}(A)$ & $P_{1}(W)$ & $V_{2}^{\prime}(V)$ & $I_{2}^{\prime}(A)$ & $P_{2}(W)$ & $V_{3}^{\prime}(V)$ & $I_{3}^{\prime}(V)$ & $P_{3}(W)$ & Efficiency $(\%)$ & Voltage regulation $(\%)$ \\
\hline 50 & 11.55 & 2510 & 210.8 & 5.60 & 1175 & 210.8 & 5.90 & 1240 & 96.22 & 4.18 \\
60 & 13.50 & 2940 & 210.0 & 6.50 & 1360 & 210.0 & 6.95 & 1455 & 95.75 & 4.55 \\
70 & 15.30 & 3350 & 209.0 & 7.45 & 1550 & 209.0 & 7.85 & 1640 & 95.22 & 5.00 \\
80 & 18.00 & 3900 & 206.4 & 8.95 & 1840 & 206.4 & 9.05 & 1860 & 94.87 & 6.18 \\
90 & 20.20 & 4400 & 205.6 & 10.20 & 2095 & 205.6 & 10.00 & 2050 & 94.21 & 6.55 \\
100 & 22.10 & 4800 & 204.4 & 11.05 & 2255 & 204.4 & 11.00 & 2240 & 93.65 & 7.09 \\
\hline
\end{tabular}

Table 2. Directly measured parameters and performance.

\begin{tabular}{cccccccccccc}
\hline Parameters $(\Omega)$ & $r_{1}(\Omega)$ & $x_{1}(\Omega)$ & $x_{23}^{\prime}(\Omega)$ & $r_{2}^{\prime}(\Omega)$ & $x_{2}^{\prime}(\Omega)$ & $r_{3}^{\prime}(\Omega)$ & $x_{3}^{\prime}(\Omega)$ & $R_{c}(\Omega)$ & $X_{c}(\Omega)$ & Efficiency (\%) & Voltage regulation $(\%)$ \\
\hline Measured $^{\mathrm{a}}$ & 0.3073 & 0.3914 & - & 0.5700 & 0.2796 & 0.6400 & 0.0517 & 1058.0 & 263.3 & 93.05 & 6.70 \\
Measured $^{\mathrm{b}}$ & - & - & - & -- & - & - & - & - & - & 93.65 & 7.09 \\
\hline
\end{tabular}

${ }^{\mathrm{a}}$ Parameters measured from $\mathrm{OC}$ and $\mathrm{SC}$ tests...; ${ }^{\mathrm{b}} \mathrm{Full}$ load performance directly measured from load test.

Table 3. Parameter used for BFA method.

\begin{tabular}{lc}
\hline \multicolumn{1}{c}{ Parameter } & Value \\
\hline Number of bacterium $(s)$ & 20 \\
Number of chemotatic steps $\left(N_{c}\right)$ & 10 \\
Swimming length $\left(N_{s}\right)$ & 4 \\
Number of reproduction steps $\left(N_{r e}\right)$ & 4 \\
Number of elimination and dispersal events $\left(N_{e d}\right)$ & 5 \\
Depth of attractant $\left(d_{\text {attract }}\right)$ & 0.1 \\
Width of attractant $\left(\omega_{\text {attract }}\right)$ & 0.2 \\
Height of repellent $\left(h_{\text {repellant }}\right)$ & 0.1 \\
Width of repellent $\left(\omega_{\text {repellant }}\right)$ & 10 \\
Probability of elimination-dispersal events $\left(P_{e d}\right)$ & 0.02 \\
\hline
\end{tabular}

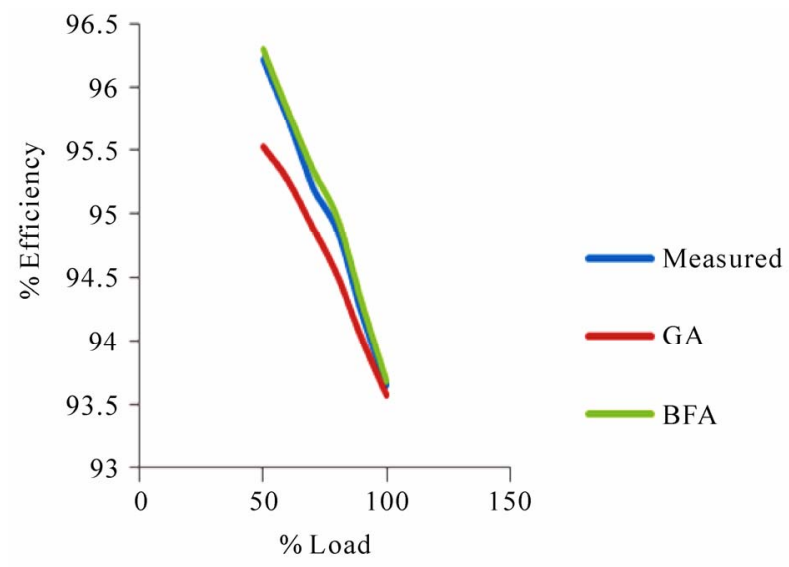

Figure 5. Performance curve of efficiency.
Table 4. Comparison of estimated parameters of TWT using GA, BFA with measured data.

\begin{tabular}{lccc}
\hline \multirow{2}{*}{ Parameters } & \multirow{2}{*}{ Measured } & \multicolumn{2}{c}{ Estimated } \\
\cline { 3 - 4 } & & GA & BFA \\
\hline$r_{1}(\Omega)$ & - & 0.2733 & 0.2810 \\
$x_{1}(\Omega)$ & - & 0.4381 & 0.4223 \\
$x_{23}^{\prime}(\Omega)$ & - & 0.3987 & 0.3572 \\
$r_{2}^{\prime}(\Omega)$ & - & 0.5376 & 0.5468 \\
$x_{2}^{\prime}(\Omega)$ & - & 0.4981 & 0.5122 \\
$r_{3}^{\prime}(\Omega)$ & - & 0.6038 & 0.5943 \\
$x_{3}^{\prime}(\Omega)$ & - & 0.4491 & 0.4238 \\
$R_{c}(\Omega)$ & - & 1121.1 & 1121.1 \\
$X_{c}(\Omega)$ & - & 265.3 & 264.2 \\
Efficiency (\%) & 93.65 & 93.57 & 93.68 \\
Voltage regulation $(\%)$ & 7.09 & 7.10 & 7.02 \\
\hline
\end{tabular}

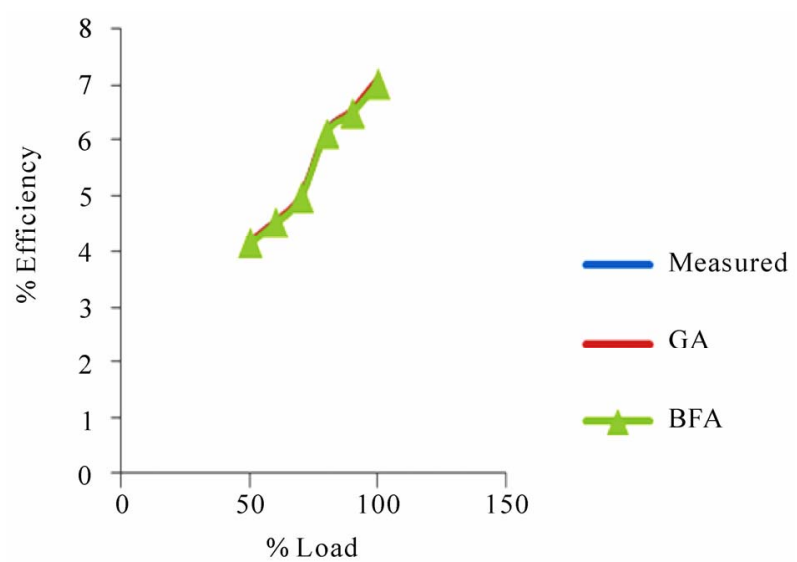

Figure 6. Performance curve of regulation. 
Table 5. Comparison of performance of TWT using GA, BFA against with directly measured data.

\begin{tabular}{|c|c|c|c|c|c|c|c|c|c|c|}
\hline \multirow{2}{*}{ \% Load } & \multicolumn{5}{|c|}{ Efficiency (\%) } & \multicolumn{5}{|c|}{ Regulation (\%) } \\
\hline & Measured & GA & \% Error & BFA & \% Error & Measured & GA & \% Error & BFA & \% Error \\
\hline 50 & 96.22 & 95.52 & -0.72 & 96.29 & 0.07 & 4.18 & 4.15 & -0.58 & 4.14 & -0.96 \\
\hline 60 & 95.75 & 95.26 & -0.51 & 95.81 & 0.06 & 4.55 & 4.53 & -0.37 & 4.510 & -0.89 \\
\hline 70 & 95.22 & 94.89 & -0.34 & 95.35 & 0.13 & 5 & 4.99 & -0.17 & 4.97 & -0.6 \\
\hline 80 & 94.87 & 94.51 & -0.37 & 94.97 & 0.04 & 6.18 & 6.14 & -0.55 & 6.12 & -0.97 \\
\hline 90 & 94.21 & 94.01 & -0.21 & 94.30 & 0.09 & 6.55 & 6.54 & -014 & 6.49 & -0.91 \\
\hline 100 & 93.65 & 93.57 & -0.08 & 93.68 & 0.03 & 7.09 & 7.10 & 0.14 & 7.02 & -0.98 \\
\hline
\end{tabular}

actual load test values, GA and BFA method. It is obvious that the performance characteristics of the sample transformer using BFA based parameter estimation method shows the better performance than other optimization method.

\section{Conclusions}

In this article, the BFA has been suggested to estimate the equivalent parameters of TWT. The equivalent circuit parameters obtained by OC and SC tests. The calculated performance characteristics such as efficiency and voltage regulation by using these parameters differ with the values of load test which indicates that the calculated parameters are inaccurate. The problem has been formulated as an error minimization problem and the modern heuristic search technique namely; BFA has been applied to estimate the accurate equivalent circuit parameters. The feasibility of the proposed technique has been tested with single phase three winding transformer, and the results are compared with actual load test values and GA based results. From this comparative study, it clearly indicates that the proposed method provides an accurate estimate of equivalent circuit parameters hence an improvement in the performance characteristics. The proposed method having the merits such as less mathematical burden, accurate estimate, high quality solution, fast convergence and less computational time. The proposed method can be applied to any capacity of transformer. The BFA technique promises to be quite efficient in solving highly nonlinear optimization problem so its application in some other fields may also be tried.

\section{Acknowledgements}

The authors are grateful to the authorities of Annamalai University for providing all facilities to carry out this work.

\section{References}

[1] S. H. Thilagar and G. S. Rao, "Parameter Estimation of
Three-Winding Transformer Using Genetic Algorithm," Engineering Applications of Artificial Intelligence, Vol. 15, No. 5, 2002, pp. 429-437. doi:10.1016/S0952-1976(02)00087-8

[2] B. A. Mork, "Five-Legged Wound-Core Transformer Model: Derivation, Parameters, Implementation, and Evaluation," IEEE Transactions on Power Delivery, Vol. 14, No. 4, 1999, pp. 1519-1525. doi:10.1109/61.796249

[3] X. S. Chen and S. S. Venkata, "A Three-Phase ThreeWinding Core-Type Transformer Model for Low-Frequency Transient Studies," IEEE Transactions on Power Delivery, Vol. 12, No. 2, 1997, pp. 775-781. doi:10.1109/61.584369

[4] H. K. M. Youssef and K. M. Naggar, "Genetic-Based Algorithm for Identification Synchronous Machine Parameter Using Short Circuit Tests," International Journal of Energy Research, 2000, Vol. 24, No. 10, pp. 877-885. doi:10.1002/1099-114X(200008)24:10<877::AID-ER630 $>3.0 . \mathrm{CO} ; 2-8$

[5] P. Pillay, V. Levin, P. Otaduy and J. Kueck, "In-Situ Induction Motor Efficiency Determination Using the Genetic Algorithm," IEEE Transactions on Energy Conversion, Vol. 13, No. 4, 1998, pp. 326-333. doi: $10.1109 / 60.736318$

[6] B. abdelhadi, A. Benoudijit and N. Nait-Said, "Application of Genetic Algorithm with a Novel Adaptive Scheme for the Identification of Induction Machine Parameters," IEEE Transactions on Energy Conversion, Vol. 20, No. 2, 2005, pp. 284-291.

doi:10.1109/TEC.2004.841508

[7] S. H. Thilagar and G. S. Rao, "In-Situ Determination of Transformer Winding Temperature Rise Using Genetic Algorithm Based Parameter Estimation," Proceedings of the International Conference Electrical and Computer Engineering, Dhaka, 26-28 December 2002, pp. 91-94.

[8] B. L. Peacock, M. Steurer, J. Langston, T. Baldwin and S. Henry, "Estimation of Parameters for Digital Modelling of Saturation Effects for a Transformer Model for a Real-Time Simulator," Proceedings of the 41st Southeastern Symposium System Theory, University of Tennessee Space Institute Tullahoma, USA, 15-17 March 2009, pp. 306-310. doi: 10.1109/SSST.2009.4806811

[9] S. A. Soliman, R. A. Alammari and M. A. Mostafa, "On-Line Estimation of Transformer Model Parameters," Proceedings of the Large Engineering System, Halifax, 
28-30 July 2004, pp. 170-178. doi: 10.1109/LESCPE.2004.1356295

[10] F. Alonge, F. D'lppolito, G. Ferrante and F. M. Raimondi, "Parameter Identification of Induction Motor Model Using Genetic Algorithms," IEE Proceedings on Control Theory Applications, Vol. 145, No. 6, 1998, pp. 587-597. doi:10.1049/ip-cta: 19982408

[11] J. Wang, A. F. Witulski, J. L. Vollin, T. K. Phelps and G. I. Cardwell, "Derivation, Calculation and Measurement of Parameters for a Multi-Winding Transformer Electrical Model," Proceedings of Applied Power Electronics, Dallas, 14-18 March 1999, pp. 220-226. doi: 10.1109/APEC.1999.749513

[12] R. K. Ursem and Vadstrup, "Parameter Identification of Induction Motors Using Differential Evolution," Proceedings of Evolutionary Computation, Canberra, 8-12 December 2003, pp. 790-796. doi: 10.1109/CEC.2003.1299748

[13] K. S. Huang, W. Kent, Q. H. Wu and D. R. Turner, "Parameter Identification of an Induction Machine Using Genetic Algorithms," Proceedings of the Computer Aided Control System Design, USA, 22-27 August, 1999, pp. 510-515. doi: 10.1109/CACSD.1999.808700

[14] A. Keyhani, A. Tsai and S. Sebo, "Modeling and Parameter Estimation of Power Transformers for the Study of High Frequency System Transients," Proceedings of Circuits and Systems, Champaign, 14-16 August 1989, pp. 258-264. doi: 10.1109/MWSCAS.1989.101842

[15] P. Y. Chung, M. Dolent and R. D. Lorenz, "Parameter Identification for Induction Machines by Continuous $\mathrm{Ge}-$ netic Algorithms," Proceedings ANNIE, St. Louis, 5-8 November 2000, pp. 1-13.

[16] O. Amoda, D. Tylavsky, G. McCulla and W. Knuth, "Sensitivity of Estimated Parameters in Transformer Thermal Modeling," Proceedings NAPS, Starkville, 4-6 October 2009, pp. 1-6. doi: 10.1109/NAPS.2009.5484079

[17] D. Meister and M. A. G. de Oliveira, "The Use of the Least Squares Method to Estimate the Model Parameters of a Transformer," Proceedings of Electrical Power Quality and Utilization, Lodz, 15-17 September 2009, pp. 1-6. doi: 10.1109/EPQU.2009.5318853

[18] A. Suppitaksakul and V. Saelee, "Application of Artificial Neural Networks for Electrical Losses Estimation in Three-Phase Transformer," Proceedings of Electrical
Engineering/Electronics, Computer, Telecommunications and Information Technology, Pattaya, 6-9 May 2009, pp. 248-251. doi: 10.1109/ECTICON.2009.5137002

[19] J. J. Wu, H. Sugimoto and C. K. Wang, "Parameter Estimate Modeling of Electronic Transformer," Proceedings of Power Electronics and Motion Control, Shanghai, 14-16 August 2006, pp. 1-8. doi: 10.1109/IPEMC.2006.4778192

[20] M. R. Feyzi and M. Sabahi, "Online Dynamic Parameter Estimation of Transformer Equivalent Circuit," Proceedings of Power Electronics and Motion Control, Shanghai, 14-16 August 2006, pp. 1-5. doi: 10.1109/IPEMC.2006.4778186

[21] B. K. Panigrahi and V. R. Pandi, "Bacterial Foraging Optimisation: Nelder-Mead Hybrid Algorithm for Economic Load Dispatch," IET Generation, Transmission and Distribution, Vol. 2, No. 4, 2008, pp. 556-565. doi:10.1049/iet-gtd:20070422

[22] M. Tripathy and S. Mishra, "Bacteria Foraging Based Solution to Optimize Both Real Power Loss and Voltage Stability Limit," IEEE Transaction on Power Systems, Vol. 22, No. 1, 2007, pp. 240-248. doi:10.1109/TPWRS.2006.887968

[23] W. J. Tang, Q. H. Wu and J. R. Saunders, "Bacterial Foraging Algorithm for Dynamic Environments," Proceedings of the IEEE Congress Evolutionary Computation, Canada, 16-21 July 2006, pp. 1324-1330. doi: 10.1109/CEC.2006.1688462

[24] D. P. Acharya, G. Panda, S. Mishra and Y. V. S. Lakshmi, "Bacteria Foraging Based Independent Component Analysis," Proceeding of the Computational Intelligence and Multimedia Applications, Sivakasi, 13-15 December, 2007, pp. 527-531. doi: 10.1109/ICCIMA.2007.126

[25] G. Noriega, J. Restrepo, V. Guzmán, M. Gimenez and J. Aller, "On-Line Parameter Estimation of Electric Systems Using the Bacterial Foraging Algorithm," Proceedings of the Power Electronics and Applications, Barcelona, 8-10 September 2009, pp. 1-7.

[26] P. G. Kou, J. Z. Zhou, C. S. Li, Y. Y. He and H. He, "Identification of Hydraulic Turbine Governor System Parameters Based on Bacterial Foraging Optimization Algorithm," Proceedings of the Natural Computation, ICNC, Shandong, 10-12 August 2010, pp. 3339-3343. doi: 10.1109/ICNC.2010.5583639 


\section{Nomenclature}

$C(i)$
$i$
$j$
$J(i, j, k, l)$
$J_{c c}$
$J_{\text {health }}^{i}$
$k$
$l$
$m$
$N_{c}$
$N_{e d}$
$N_{r e}$
$N_{s}$
$P$
$P_{\text {ed }}$
$s_{\theta^{i}(j, k, l)}$
$r_{2}^{\prime}$
$x_{2}^{\prime}$
$\omega_{\text {attract }}^{\prime}$
$\omega_{\text {repellant }}$
$h_{\text {repellent }}$
$d_{\text {attract }}$
$r_{1}$
$x_{1}$

Step size

Bacterium number

Counter for chemotactic step

Cost at the location of $i^{\text {th }}$ bacterium

Swarm attractant cost

Health of bacterium $i$

Counter for reproduction step

Counter for elimination-dispersal step

Counter for swimming locomotion

Maximum number of chemotactic steps

Number of elimination-dispersal events

Maximum number of reproduction steps

Maximum number of swims

Dimension of the optimization problem

Probability of occurrence of eliminationdispersal events

Population of the E. coli bacteria

Location of the $i^{\text {th }}$ bacterium at $j^{\text {th }}$ chemotactic step, $k^{\text {th }}$ reproduction step, and $l$ the elimination-dispersal step

Width of attractant

Width of repellent

Height of repellent

Depth of attract

Resistance of the primary winding $(\Omega)$

Leakage reactance of the primary winding $(\Omega)$

Mutual leakage reactance between secondary and tertiary windings referred to primary side $(\Omega)$.

Resistance of the secondary winding referred to primary side $(\Omega)$

Leakage reactance of the secondary winding referred to primary side $(\Omega)$

$r_{3}^{\prime} \quad$ Resistance of the tertiary winding referred to primary side $(\Omega)$

$x_{3}^{\prime} \quad$ Leakage reactance of the tertiary winding referred to primary side $(\Omega)$

$R_{c} \quad$ Core loss equivalent resistance $(\Omega)$

$X_{c} \quad$ Magnetizing reactance $(\Omega)$

$r_{l 2}^{\prime}$ and $r_{l 3}^{\prime} \quad$ Load resistances of secondary and tertiary side referred to primary side $(\Omega)$

$z_{1}, z_{2}, z_{3} \quad$ Measured Primary, secondary and tertiary side impedances respectively $(\Omega)$

$z_{2}^{\prime}$ and $z_{3}^{\prime} \quad$ Secondary and tertiary side impedance referred to primary side $(\Omega)$

$z_{\text {lest }} \quad$ Estimated Primary side impedance $(\Omega)$

$V_{1 \text { mes }}, V_{2 \text { mes }}^{\prime}, V_{3 \text { mes }}^{\prime} \quad$ Measured value of primary, secondary and tertiary voltage referred to primary side $(\mathrm{V})$

$I_{1}, I_{2}^{\prime}, I_{3}^{\prime} \quad$ Measured value of primary, secondary and tertiary current referred to primary side (A)

$V_{\text {lest }} \quad$ Estimated value of primary voltage (V)

$E_{1} \quad$ Voltage across the magnetizing winding (V)

$I_{m} \quad$ Current through the magnetizing winding (A)

$P_{1 m e s} \quad$ Measured value of power in primary side (W)

$P_{1 e s t} \quad$ Estimated value of power in primary side (W)

$P_{1}, P_{2}, P_{3} \quad$ Measured values of power primary, secondary and tertiary side (W)

$P_{1 c u}, P_{2 c u}, P_{3 c u}$ Copper loss components of primary, secondary and tertiary side (W)

$P_{\text {core }} \quad$ Core loss component (W) 